\section{CIUDADANÍA GLOBAL. UN ESTUDIO SOBRE LAS IDENTIDADES SOCIOPOLÍTICAS EN UN MUNDO INTERCONECTADO}

\author{
Antonio Martín-Cabello \\ Universidad Rey Juan Carlos \\ ORCID iD: http://orcid.org/0000-0002-3832-4663 \\ antonio.martin@urjc.es
}

Cómo citar este artículo/Citation: Martín-Cabello, A. (2017). Ciudadanía global. Un estudio sobre las identidades sociopolíticas en un mundo interconectado. Arbor, 193 (786): a422. doi: http:// dx.doi.org/10.3989/arbor.2017.786n4010

Recibido: 7 mayo 2016. Aceptado: 6 marzo 2017.

RESUMEN: Este artículo pretende realizar un estudio sobre la posible aparición de un nuevo tipo de ciudadanía: la ciudadanía global. Buena parte de la bibliografía de ciencias sociales lleva tiempo anunciando el debilitamiento del estado-nación y de la ciudadanía nacional como resultado del proceso de globalización. La consecuencia sería el aumento del cosmopolitismo y la emergencia de una identidad ciudadana global. Esta sería, en principio, especialmente acusada entre los colectivos más globalizados. En el artículo se analizarán dos: los mochileros y los expatriados corporativos. Sin embargo, se intentará mostrar que cuando se utiliza la evidencia empírica disponible existen rasgos contradictorios. Tanto los mochileros como los expatriados corporativos comparten una retórica cosmopolita que no tiene un correlato tan claro en la esfera de las prácticas.

PALABRAS CLAVE: Globalización; ciudadanía; ciudadanía global; cosmopolitismo; elites globales.

\section{GLOBAL CITIZENSHIP. A STUDY ON THE SOCIO- POLITICAL IDENTITIES IN AN INTERCONNECTED WORLD}

Copyright: @ 2017 CSIC. Este es un artículo de acceso abierto distribuido bajo los términos de la licencia Creative Commons Attribution (CC BY) España 3.0.

ABSTRACT: This paper aims to study the possible emergence of a new type of citizenship: global citizenship. For some time much of the literature in social science has related a weakening of nation-state and national-citizenship as a result of the globalization process. The consequence would be an increase in cosmopolitanism and emergence of a global citizenship identity. This, in principle, would be especially pronounced amongst the most globalized groups. The paper discusses two of these: backpackers and corporate expatriates. However, we show here that contradictory features arise when the available empirical evidence is studied. Both backpackers and corporate expatriates share a cosmopolitan rhetoric that has no clear correlation with the areas of social practice.

KEYWORDS: Globalization; citizenship; global citizenship; cosmopolitanism; global elites. 


\section{INTRODUCCIÓN}

La idea moderna de ciudadanía supone un vínculo político y jurídico entre un estado y los miembros del mismo. En cuanto tales, los individuos son poseedores de derechos-cívicos, políticos o sociales (Marshall y Bottomore, 1998)- y deberes -tributarios, electorales 0 , entre otros, militares-. En consecuencia, la ciudadanía supone la inclusión de ciertos individuos en una comunidad política y, de modo paralelo, la exclusión de otros. También es, y de una forma crucial, una forma de identidad sociopolítica, ya que implica vínculos sentimentales y de lealtad por parte del ciudadano respecto del estado al cual pertenece (Heater, 2007 , p. 13). Sería posible, por tanto, definir el concepto como "un estatus político y jurídico relacionado con un estado que integra a las personas afectadas, al mismo tiempo que las dota de una identidad política, en un contexto sociocultural y en un determinado territorio y que desarrolla sujetos políticos activos y participativos" (González García y Chacón-López, 2014, p. 307). La ciudanía implica tanto una dimensión formal como sustantiva, es decir, es tanto un estatus como una práctica ciudadana (Díaz Velázquez, 2009).

Tradicionalmente se consideraba que la ciudadanía se vinculaba con el estado-nación ${ }^{1}$, lo que denominaremos ciudadanía nacional. Sin duda, el concepto de ciudanía nacional surgió y se desarrolló junto al estado moderno. Los estados democráticos han tendido a constituirse en torno a naciones y la idea de ciudadanía ha estado ligada al principio nacional (SánchezCuenca, 2010, cap. 2; Sánchez-Cuenca, 2016, pp. 124 y ss.). Reinhard Bendix (1974) mantenía que durante la Edad Media no todos los individuos tenían la capacidad de relacionarse directamente con el estado. La creación del estado moderno supuso la extensión de esa capacidad a los individuos adultos que vivían bajo su paraguas. Se pensaba que el estado era la única fuente de derechos y deberes y que la idea de una ciudadanía cosmopolita, por atractiva y justa que fuera, estaba ligada más a la esfera de la ética. Como nos recuerda Tzvetan Todorov, Jean Jacques Rousseau así lo creía:

Las expresiones "derechos del hombre" y "ciudadano del mundo" encierran, una y otra, una contradicción interna: para poder gozar de derechos es preciso ser, no hombre, sino ciudadano; pero (...)- únicamente los estados poseen ciudadanos, y no el mundo. Estar a favor del derecho implica que se está del lado del ciudadano y, sin embargo, el mejor principio de justicia es el de la universalidad (Todorov, 2010, p. 215).
El estado moderno, en consecuencia, era "la fuente originaria de los derechos de ciudadanía, y estos derechos contienen un signo de igualdad nacional" (Levín, 2004 , p. 45) y la idea de pueblo y de ciudadanía eran las dos caras del estado-nación (Vior, 2011, p. 255). La cultura nacional trasmitida a través de la educación resultaba necesaria para inculcar y fomentar los valores cívicos en los individuos.

En los últimos tiempos, sin embargo, se comienza a dudar de esta relación y muchas veces se contrapone la identidad nacional a la identidad ciudadana. Se argumenta que la nación definida en términos culturales, como hace cierto tipo de nacionalismo, es incompatible con la noción de ciudadanía². Solamente una nación definida en términos políticos lo sería. Así, una voz tan reputada como la de Jürgen Habermas acuñó la noción de patriotismo constitucional para rechazar la vinculación sentimental a la nación cultural como base de la identidad sociopolítica. Para Habermas:

El patriotismo constitucional al poner el acento en la adhesión en los fundamentos del régimen político democrático, y no tanto en la comunión con los substratos prepolíticos de una comunidad étnico-nacional, se encontraría en condiciones de estrechar la cohesión entre los diversos grupos culturales y consolidar una cultura política de la tolerancia que posibilite la coexistencia intercultural (Velasco, 2003, p. 138).

En este caso, la ciudadanía no se ligaría a la nación como entidad étnico-cultural, sino a los valores democráticos recogidos en la constitución. La nación definida en términos culturales se presenta como algo contrapuesto a una nación basada en valores cívicos y republicanos.

Pretendemos revisar a lo largo de este artículo cómo estas nociones se relacionan con la posible aparición de una ciudadanía global. El artículo pretende ser lo que Richard Swedberg denomina un "estudio previo" en el cual se tratan de hallar relaciones creativas en base a una "breve pero intensa confrontación con los datos" (Swedberg, 2016, p. 34). En el mismo intento contrastamos las teorías más difundidas sobre la ciudadanía global con la evidencia empírica disponible acerca del sentimiento cosmopolita, tanto entre el grueso de la población mundial como, especialmente, entre ciertos colectivos globalizados. El objetivo es detectar la presencia de un mayor cosmopolitismo entre estos últimos.

Respecto a la terminología empleada se utilizarán los conceptos de ciudadanía nacional, definido más adelante, y los de ciudadanía global, ciudadanía 
mundial o ciudadanía cosmopolita. Estos tres últimos operarán como sinónimos en todo el texto. El concepto de cosmopolitismo se entenderá en una doble dimensión: individual e institucional. En ambos casos, como se verá, este puede operar como una ideología o como una práctica.

En lo que sigue trataremos de arrojar algo de luz sobre alguna de estas cuestiones en modo alguno sencillas. Para ello, en primer lugar, revisaremos la relación entre el concepto de identidad social y el proceso de globalización. Se mantendrá que la ciudadanía ha sido, y es, una de las principales fuentes de identidad, si bien el proceso de globalización hace que otros criterios adquieran importancia a la hora de definir la identidad sociopolítica de los individuos. En segundo lugar, describiremos los factores que según la teoría circulante inciden en que la ciudadanía ligada al estado-nación, la ciudadanía nacional, se esté debilitando. En tercer lugar, reflexionaremos sobre la posible aparición de una ciudadanía global que complemente o sustituya a la debilitada ciudadanía nacional. Después se revisarán las evidencias que las encuestas ofrecen sobre el apoyo al estado-nación y a las opciones cosmopolitas. Para terminar, nos centraremos en dos colectivos: los mochileros y los expatriados corporativos, que viven la globalización de un modo destacado. El objetivo es intentar discernir, usando la evidencia empírica disponible, si entre ellos está surgiendo una identidad ciudadana global o si por el contrario prevalece aún la identidad ciudadana nacional.

\section{GLOBALIZACIÓN E IDENTIDAD}

El proceso de globalización ha sido ampliamente explorado en la bibliografía científica (p. ej. Bauman, 2010; Beck, 2008; Giddens, 2002). Este afecta a todas las esferas de la vida social, cultural, política y, claro está, económica. La globalización de la cultura está produciendo importantes cambios en las culturas nacionales y locales en todo el planeta y en los procesos identitarios asociados a las mismas. Renato Ortiz (1998) hablaba de "modernidad mundo" para referirse a las tendencias a la homogeneización, que afectan a ciertos espacios desterritorializados del planeta. Existe un espacio homogéneo, fruto de la modernidad mundo, frente a la pluralidad de culturas locales. Un espacio que pugna por ser hegemónico. Existe, asimismo, una tendencia a la generación de una "memoria colectiva internacional popular", frente a la "memoria colectiva nacional popular".

Los artífices de la memoria nacional fueron el estado y la escuela. (...) Los artífices de la memoria inter- nacional popular son, en primer lugar, los medios de las transnacionales, quienes tienen la capacidad de generar un conjunto de imágenes que se transforman en referentes culturales (Ortiz, 1998, p. 64).

Esta cultura transnacional, afirma, tiende a enfrentarse con las culturas nacionales enclavadas en lo local. Se está produciendo, por tanto, una homogeneización occidentalizante que encarna mayoritariamente ciertos valores o líneas de fuerza como, por ejemplo, el individualismo o el consumismo. Esta homogeneización se ve contestada por fuerzas de carácter local, que enfatizan la diferenciación. La amplia mayoría de los científicos sociales confirman la existencia de una dinámica de homogeneización cultural, de un lado, y de diferenciación, de otro, que opera entre lo local y lo global. El reto, para la mayoría de ellos, como afirma Peter L. Berger "lo plantea una cultura global emergente, de procedencia occidental en su mayor parte (estadounidense, en realidad), que penetra en el resto del mundo tanto en el nivel de la elite como en el nivel popular" (Berger y Huntington, 2002, p. 13).

La construcción de la identidad social, en consecuencia, se ve afectada de un modo notable por esta cultura de carácter global, que es aceptada, rechazada o negociada por los individuos. En el mundo actual se producen paradojas identitarias que hacen que "algunos parecen estar demasiado seguros de quiénes son, mientras que otros lo están muy poco" (Eagleton, 2001, p. 116). Esto es así porque las identidades se construyen a partir de múltiples capas: género, edad, comunidad de pertenencia o, entre otras, culturas del gusto y del consumo (Hormigos Ruiz y Oda Ángel, 2014, pp. 246-248), que no se eligen racional y voluntariamente, pero que tampoco son irracionales e involuntarias. Pensar lo contrario es entrar en lo que Amartya Sen (2007) denomina la falacia de las opciones identitarias singularistas. Los individuos poseen cierta capacidad de negociar con su entorno cultural y de construir su identidad. La identidad, por tanto, no es un proceso sujeto a un automatismo que obligue a su asunción acrítica. El individuo no es un mero portador de estructuras. Y, paradójicamente, tampoco es un proceso plenamente electivo. La identidad se encuentra estructurada socialmente y en torno a esas estructuras los individuos negocian su posición.

Existe, sin embargo, cierto debate sobre la existencia de una identidad primaria que dé sentido a todas las demás identidades. Algunos autores afirman que no existe tal cosa, sino que las identidades funcionan en paralelo. Amin Maalouf aseveraba que la identidad 
está hecha de múltiples capas. No hay una esencia que sea la fuente última de la misma.

"En todas las épocas hubo gentes que nos hacen pensar que había entonces una sola pertenencia primordial, tan superior a las demás en todas las circunstancias que estaba justificado denominarla «identidad». La religión para unos, la nación o la clase social para otros. En la actualidad, sin embargo, basta con echar una mirada a los diferentes conflictos que se están produciendo en el mundo para advertir que no hay una única pertenencia que se imponga de manera absoluta sobre las demás" (Maalouf, 2010, p. 21).

Puede existir una jerarquía entre las lealtades de los individuos, pero no es inmutable y de hecho varía, como demuestra la experiencia real de muchas personas. La etnia, la religión, la nación, el género o la edad pueden ser más o menos importantes para las personas en diferentes momentos en función de las circunstancias sociales e históricas en las cuales se muevan.

Otros estudiosos, por el contrario, sostienen que es posible encontrar una jerarquía dentro de las posibles identidades sociales que puede adoptar el individuo. Existe una identidad que engloba las demás. Manuel Castells así lo cree cuando afirma:

Para un individuo determinado o un actor colectivo puede haber una pluralidad de identidades. No obstante, tal pluralidad es una fuente de tensión y contradicción tanto en la representación de uno mismo como en la acción social. (...) En la sociedad red, (...), para la mayoría de los actores sociales, el sentido se organiza en torno a una identidad primaria (es decir, una identidad que enmarca el resto), que se sostiene por sí misma a lo largo del tiempo y el espacio (Castells, 2000, pp. 28-29, cursiva del propio autor).

De lo anterior puede mantenerse que existen múltiples fuentes identitarias conformadas históricamente. La nación, la ciudadanía, la etnia, la raza o cualquier otro criterio pueden ser base de la identidad social. También podría añadirse que la cultura global puede ser un nuevo factor de identidad social que pugna con los tradicionales. Uno de los principales criterios de base para construir la identidad sociopolítica, al menos durante los últimos 300 años, ha sido el de ciudadanía. Y es un concepto que está siendo puesto en duda. Se considera, precisamente, que la cultura global auspiciada por el proceso de globalización es un poderoso diluyente de una noción primaria de la identidad en torno al concepto de ciudadanía y de la vinculación del estado-nación con la ciudadanía.

\section{EL DEBILITAMIENTO DE LA CIUDADANÍA NACIONAL COMO IDENTIDAD SOCIOPOLÍTICA}

El de ciudadanía, como hemos mantenido más arriba, es uno de los criterios a través de los cuales puede configurarse la identidad social de los individuos. Ahora bien, los defensores del concepto de identidades múltiples afirman que en la actualidad se está produciendo un debilitamiento de la ciudadanía nacional tradicional como criterio básico a la hora de configurar la identidad sociopolítica. Esta debilidad se produciría en dos esferas. Por un lado, la presencia de grupos étnicos y nacionales diferenciales dentro de los estados desvincularía a la ciudadanía del estadonación. Y, por otro lado, la apertura de fronteras y la integración supranacional permitirían la aparición de ciudanías coexistentes o superpuestas. La primera tendencia puede denominarse la crisis de la identidad nacional y la segunda la ciudadanía débil.

\subsection{Crisis de la identidad nacional}

La existencia de grupos étnicos o nacionales con identidades diferenciales $y$, a veces, enfrentadas a la identidad ciudadana del estado-nación puede ocasionar que esta última se debilite. Por un lado, los estados plurinacionales son más la realidad que la excepción. La idea de un estado-nación con una identidad cívica unitaria parece más un sueño que una realidad en la mayor parte de los casos. En varias de las viejas naciones europeas coexisten diversas identidades nacionales bajo el paraguas de un mismo estado (Lamo de Espinosa, 1996). Esto puede generar conflictos identitarios marcados, sobre todo cuando las naciones incluidas en el estado plurinacional reclaman para sí un estado y una identidad cívica propia. El caso del nacionalismo escocés, vasco o catalán, por citar apenas los más evidentes, puede ejemplificar bien esta situación.

Los nacionalismos tienden a definirse por contraposición y es habitual que el nacionalismo regional emergente intente definir a sus ciudadanos frente a los ciudadanos del estado en el cual se encuentran inmersos en la actualidad. Aunque, en algunos casos, se plantea la posibilidad de mantener una doble nacionalidad una vez que se alcanzase la independencia política. En todo caso, parece claro que las lealtades nacionales regionales pueden suponer un menoscabo de una identidad ciudadana nacional.

Por otro lado, la llegada de grupos étnicos vía inmigración puede suponer un desafío a la identidad cívica dominante (Castles y Davidson, 2000). En Francia, por ejemplo, los temores ante la llegada de inmigrantes musulmanes -algunos asentados en el país desde 
hace años- han generado una gran polémica en torno a los valores republicanos. La cuestión del velo en la escuela resonó en la prensa de medio mundo. La idea era que los valores de los musulmanes resultaban incompatibles con la concepción de la ciudadanía francesa tradicional. La pérdida de la identidad cívica republicana francesa a manos de los inmigrantes musulmanes ha sido incluso novelada con éxito por Michel Houellebecq (2015). En este libro presenta la victoria electoral de un partido islamista en Francia que trata de subvertir los sagrados valores republicanos.

Dentro de los Estados Unidos surgen temores similares respecto a otro colectivo de inmigrantes. En este caso, el principal signo distintivo no sería la religión, sino que la polémica se centraría en la lengua y las costumbres de los inmigrantes latinos. El politólogo estadounidense Samuel P. Huntington mostró en su libro ¿Quiénes somos? (2004) el miedo provocado por la "invasión" que sufre su país por parte de un grupo étnico: los latinoamericanos, en especial los mexicanos, que consideraba no asimilables como ciudadanos. En el pasado los inmigrantes fueron asimilados con éxito, pero por una serie de razones que enumera en su obra considera que estos no lo son ${ }^{3}$.

En ambos casos se argumenta que o bien el enemigo interior (nacionalismos regionales) o bien exterior (inmigrantes) atacan la identidad cívica asociada al estado-nación. Y que este, por tanto, pierde fuerza y se ve disminuido. La globalización, aseguran, estaría detrás de ambos fenómenos, ya que favorece la pérdida de soberanía nacional frente a otras instancias, y da pie a las reclamaciones de las comunidades (Bokser, 2006, p. 169; Münch, 2001). De todos modos, también se ha argumentado convincentemente que hablar de la "muerte del estado" es, cuanto menos, una exageración (Anderson, 1995). Este parece tener más vida de la que los teóricos de la globalización a veces parecen concederle. Y la identidad asociada al mismo parece también ser más resistente de lo que parece como se verá más adelante.

\subsection{Ciudadanía débil}

Además de las amenazas de grupos étnicos o nacionales diferenciales también se plantean supuestos peligros para la identidad nacional por el debilitamiento de los vínculos de la ciudanía con el estado que la proporciona. Estos vínculos se debilitarían cuando la ciudanía debe compartir espacios con otras ciudadanías. No se rechaza la ciudadanía como tal, pero se busca que comparta espacio con otras. Dos casos pueden ser paradigmáticos: los casos de doble nacionalidad y las identidades escalonadas propias de los estados federales. En ambos casos se trata de la aparición de ciudadanías múltiples que debilitan la visión singularista de la ciudadanía. A esto habría que añadir la desagregación del concepto de ciudadanía, pues los individuos pueden aceptar los derechos, pero no las obligaciones, o aceptar ambas cosas y, sin embargo, no sentirse identificados con el estado-nación. Es decir, el paquete completo de la ciudadanía nacional dejaría paso a una ciudadanía a la carta.

Respecto a las dobles nacionalidades se puede decir que, aunque legalmente no puedan coexistir en algunos países -otros si aceptan esta situación-, eso no implica que no pueda producirse un sentimiento de vinculación hacia dos estados. Es posible que una persona no renuncie a su nacionalidad, pero que se sienta vinculada como ciudadano con el país en el cual reside, que puede a su vez no reconocer la doble ciudadanía. La legalidad y la identidad no tienen por qué concordar (Sen, 2007, p. 56). Ambas identidades ciudadanas pueden coexistir pacíficamente o, en otras ocasiones, presas de graves contradicciones.

En los estados federales pueden cohabitar identidades ciudadanas en al menos dos escalones: el federal y el estatal. Así, un estadounidense puede sentir una vinculación cívica con Texas o Florida y, al tiempo, con Estados Unidos. En Europa a las ciudadanías nacionales se les ha sumado una ciudadanía supranacional encarnada en la Unión Europea. De este modo, además de una ciudanía nacional se habla de la aparición de una ciudadanía europea. Aunque, en este último caso, la vinculación cívica con la organización estatal supranacional parece más laxa que en el caso estadounidense. De todos modos, habría que dilucidar si la ciudadanía deriva de la pertenencia al estado-nación. Dicho de otro modo, sería necesario preguntarse si adquirimos la condición de ciudadanos europeos en cuanto ciudadanos de nuestro estado-nación. Esto parece claro en el plano jurídico y político, pero en el identitario puede no estarlo tanto.

En el caso de la Unión Europea, la ciudadanía nacional plena la poseen los miembros de un estado. Existe un segundo escalón de ciudadanía que disfrutarían los demás miembros de la Unión Europea (pueden, en algunos casos, votar y ser elegidos en las elecciones locales, regionales o para el parlamento de la Unión Europea). Y en un tercer escalón estarían los individuos de terceros países que no tienen la ciudadanía plena. Resulta significativo que algunos residentes de terceros países pueden llevar mucho tiempo residiendo en el país de acogida y, aun así, disfrutar de menos dere- 
chos que los miembros de otros estados de la Unión Europea que tienen paradójicamente una vinculación menor con el mismo (Benhabib, 2006, p. 257).

Por último, Seyla Benhabib (2006) afirma que se está produciendo un "efecto desagregación" entre los diferentes criterios que constituyen la ciudadanía. Algunos grupos de inmigrantes en países desarrollados podrían beneficiarse de los derechos de ciudadanía y, sin embargo, no ser ciudadanos de pleno derecho $y$, además, no sentirse identificados con el estado bajo el cual residen. Este hecho podría tener que ver con el proceso de individualización y personalización propio de las sociedades tardomodernas (Giddens, 1999, pp. 118-119; Lipovetsky, 2004), con los procesos de "desanclaje" de las estructuras comunales (Beck y Beck-Gernsheim, 2003) y la deslegitimación de las instituciones tradicionales, entre ellas el estado (MartínCabello, 2015). El resultado es que "Ios derechos que configuran la ciudadanía hoy son mucho más complejos que en el pasado y se tienen que adecuar a poblaciones mucho más diversificadas e individualizadas" (Borja, 2002, p. 5). Como consecuencia de lo anterior, algunos autores propugnan que la ciudadanía deja de ser un criterio de identidad prioritario y que se configura en lo que denominan una ciudadanía flexible (Ong, 1999).

En definitiva, si se suman los aprietos del estado nación (crisis de la identidad nacional) con que la ciudadanía nacional deja de ser la principal fuente de identidad social (ciudadanía débil) encontramos que el concepto tradicional de ciudadanía nacional se debilita. Como consecuencia de lo anterior, Stephen Castles (2003) sostiene que surgen, de un lado, una jerarquía de ciudadanía dentro de los estados-nación (Tabla 1) y, de otro, jerarquías de ciudadanía en función de la posición del estado-nación dentro del sistema mundial de estados.

\section{4. ¿DE LA CIUDADANÍA NACIONAL A LA CIUDADANÍA GLOBAL?}

Hasta el momento hemos comentado los problemas que la globalización crea a la ciudadanía nacional tradicional. A partir de este momento intentaremos responder a la difícil cuestión de la posible aparición de una ciudadanía global. Este asunto está íntimamente relacionado con la noción tradicional del cosmopolitismo, aunque la existencia de un proceso de globalización nos hace preguntarnos si es cierto que, como afirma Piort Sztompka (2008, p. 111), la humanidad ya no es una categoría o un agregado estadístico, sino una entidad sociológica real. Si es así, sería posible hablar de una ciudadanía global en un sentido sociológico. De otro modo, se estaría dando otro nombre al ideal cosmopolita tradicional de un ciudadano del mundo.

Múltiples autores han destacado el impacto que la globalización está teniendo sobre la noción de ciudadanía (Delanty, 2000). En especial destacan su carácter disgregador sobre la soberanía nacional y el debilitamiento que produce en la noción de ciudadanía nacional tradicional (Bokser y Salas-Porras Soulé, 1999; Castells, 2000; Castles, 2003, pp. 15-17; Girardo Jiménez, 2000). Sin embargo, no existe acuerdo sobre el impacto de la globalización en la emergencia de una ciudanía global, cosmopolita o universal. Algunos autores creen que la globalización destruye la idea de ciudadanía y que no tiene nada que ver con la idea de una ciudadanía cosmopolita (Seoane Pinilla, 2009). También se ha afirmado que la globalización neoliberal está destruyendo los derechos sociales y que impide la aparición de una ciudadanía mundial (Anchustegui Igartua, 2012). Otros ven, de un modo más optimista, en la globalización una oportunidad que permitiría un cosmopolitismo en el cual la nacionalidad y las fronteras no impiden el desarrollo de los derechos reconocidos por la justicia universal (Mandujano, 2009). De hecho, la idea de reformular o reinventar la ciudadanía a la luz de los cambios producidos por el proceso de globalización aparece constantemente en la bibliografía al respecto (Aguilera Portales, 2011; Niederberger, 2012; Parada Barrera, 2009; Santiago Juárez, 2015).

En todo caso, creemos necesario revisar los sentidos en los cuales se ha usado el cosmopolitismo y la ciudadanía mundial o universal, pues no todos los autores entienden lo mismo cuando usan la expresión ciudadanía global. En líneas generales, el ideal cosmopolita de una ciudadanía mundial tiene dos dimensiones: puede verse como un ideal ético o como un orden político real (Held, 2012).

En el primer caso, el cosmopolitismo puede contemplarse como un ideal ético. La idea clásica es la de que el cosmopolitismo es una doctrina ética según la cual los individuos tienen vinculaciones con todos los individuos del planeta. Es decir, los seres humanos son en primer lugar ciudadanos del mundo y solo de modo accidental miembros de su comunidad política. En consecuencia, han de comportase como iguales ante cualquier otro ser humano con independencia de su ciudadanía. Para Immanuel Kant, el cosmopolitismo era una actitud ética, un principio moral que afirmaba la pertenencia de los seres humanos a una 
Tabla 1. Jerarquías de ciudadanía en los estados-nación

\begin{tabular}{|l|l|}
\hline \multicolumn{1}{|c|}{ Tipos } & \multicolumn{1}{c|}{ Características } \\
\hline Ciudadanos plenos & Gente nacida en un país más inmigrantes naturalizados. \\
\hline Residentes & $\begin{array}{l}\text { Inmigrantes que han obtenido algunos derechos de ciudadanía debido a permanentes una } \\
\text { residencia duradera. }\end{array}$ \\
\hline Migrantes & $\begin{array}{l}\text { Faltan casi todos los derechos excepto aquellos garantizados para todos los } \\
\text { indocumentados por los instrumentos internacionales de derechos humanos. }\end{array}$ \\
\hline Solicitantes de asilo & Derechos muy limitados bajo regímenes especiales. \\
\hline Minorías étnicas & $\begin{array}{l}\text { Normalmente disfrutan de todos los derechos, pero pueden no ser capaces de ejercerlos } \\
\text { debido a la discriminación y la exclusión social. }\end{array}$ \\
\hline Pueblos indígenas & $\begin{array}{l}\text { Principalmente en sociedades de colonos blancos (EE. UU., Canadá, Australia, Nueva } \\
\text { Zelanda, Latinoamérica). Sujetos a procesos históricos de desposesión, discriminación } \\
\text { jurídica y exclusión social. Hoy el asunto fundamental es la exclusión social. }\end{array}$ \\
\hline Divisiones de genero & $\begin{array}{l}\text { La discriminación jurídica contra las mujeres es ahora poco común en los países del norte, } \\
\text { aunque es todavía común en el sur. La discriminación institucional e informal persiste. }\end{array}$ \\
\hline
\end{tabular}

Fuente: Castles, 2003, p. 30.

misma comunidad universal. Es cierto que habló de una federación mundial de estados, es decir, de un cosmopolitismo como un orden político real, pero consideraba la federación mundial más como un ideal al cual aspirar que como una realidad alcanzable. De hecho, la ciudadanía cosmopolita era en sus términos más una obligación moral que una realidad. En nuestro mundo creía que la ciudadanía mundial debía ceñirse al derecho a la hospitalidad (Santiago Juárez, 2009). En la actualidad este cosmopolitismo moral, sostiene David Held (2012, pp. 52-57), pivota en torno a tres grandes principios: el igualitarismo moral individualista, el reconocimiento recíproco y el razonamiento imparcial.

Asimismo, el tema del universalismo ético que implica el cosmopolitismo es controvertido. Algunos autores, como Immanuel Wallerstein (2007) han afirmado que en la actualidad no hay tal cosa, que vivimos presa de un universalismo europeo, no de un universalismo universal. Es decir, el ideal cosmopolita sería una trasposición a nivel mundial de las ideas europeas, no un ideal fruto del concurso de todos los pueblos de la tierra.

La globalización podría estar ayudando, en definitiva, a la extensión de los ideales éticos cosmopolitas, bien como fruto de un diálogo racional transnacional intensificado, o bien como fruto de la extensión de una cultura occidental globalizada con pretensiones de universalidad. En todo caso, sean cuales sean sus causas, la extensión de los ideales cosmopolitas y de la ciudadanía mundial es una cuestión de carácter empírico. En teoría la globalización debería hacer que aumentase el apoyo mundial al cosmopolitismo.

En el segundo caso, el cosmopolitismo puede verse como un orden político real. Si el concepto de ciudadanía ha estado ligado a una entidad política respecto a la cual adquiría sentido, la pregunta sería: ¿es posible la existencia de un ente supranacional real que confiera derechos y deberes y al cual los individuos puedan sentirse vinculados o es simplemente, como planteábamos antes, una figura del entendimiento? Desde esta posición se suele contestar afirmativamente, haciendo referencia a la existencia de un derecho cosmopolita (Declaración de los Derechos $\mathrm{Hu}$ manos de las Naciones Unidas), de órganos de justicia que aplican el derecho cosmopolita (la Corte Penal Internacional) y de organizaciones que tienen ya una verdadera dimensión transnacional (ONU, UNESCO, OIT), aunque muchas de ellas en su origen pudiesen surgir como acuerdos entre naciones. Algunos autores consideran que los organismos transnacionales ya están operando en clave de un cosmopolitismo real. Josep M. Colomer (2015) sostenía que en la actualidad está surgiendo un gobierno mundial basado en una gobernanza que, si bien no seguía las pautas de las democracias nacionales tradicionales, sí podía considerarse, desde su punto de vista, democrática. Para él, "la democracia se puede definir como una forma de gobierno basada en el consentimiento social que implica los valores y objetivos de la libertad, la toma de decisiones efectiva y la rendición de cuentas 
de los gobernantes" (Colomer, 2015, pp. 242-243). Es decir, las instituciones globales serían democráticas, aunque no se ajustarían a la democracia partidista nacional, y serían la base de una ciudadanía global real.

Sin embargo, otros autores consideran que no es posible considerar verdaderamente democráticas las decisiones de estas organizaciones. Robert A. Dahl afirma: "aunque los procesos democráticos puedan establecer los límites externos dentro de los cuales las élites realicen sus negociaciones, llamar a las prácticas políticas de los sistemas internacionales «democráticas» equivaldría a privar al término de toda su significación" (Dahl, 2014, p. 136). Lo cierto es que, aunque existan organizaciones transnacionales, tanto políticas como de la esfera civil, según sus críticos aún es imposible mantener que confieren derechos y deberes a los individuos tal y como hacen los estados. En este sentido, Adela Cortina (1997) considera que la ciudadanía cosmopolita funciona más como un ideal que como una descripción sociológica de nuestro mundo. Vemos, pues, que existe debate también en torno a este punto.

El proceso de globalización, en consecuencia, puede afectar al cosmopolitismo y a la ciudadanía en un doble sentido. Por un lado, puede influir en la extensión del ideal ético del cosmopolitismo y en la construcción de identidades cosmopolitas con independencia del cosmopolitismo real. Por otro lado, la creciente interconexión de las diversas sociedades del planeta podría estar generando una autoridad cosmopolita real que llevase aparejada una ciudadanía de carácter global. En el siguiente epígrafe intentaremos responder a la primera de las cuestiones, esto es, recogeremos algunas estadísticas y estudios que intentan mostrar si es posible hablar de una ciudadanía global en términos identitarios.

\section{ALGUNAS EVIDENCIAS EMPÍRICAS}

La cuestión que hemos descrito más arriba, es decir, si en la actualidad asistimos a la emergencia de una ciudadanía global o si las ciudadanías nacionales siguen siendo importantes fuentes de identidad para los individuos, solamente puede contestarse utilizando la evidencia empírica disponible. De otro modo, la discusión teórica puede hacerse eterna. Como otros autores han remarcado, es necesario que el cosmopolitismo se convierta en una categoría analítica y deje de ser un concepto difuso (Skrbis, Kendall y Woodward, 2004).

Diversos estudios muestran que el apego a la nación sigue siendo importante. La Encuesta Mundial de Va- lores así lo plantea. Cuando se pregunta a los ciudadanos de distintos países por los sentimientos de orgullo nacional, existe una gran diversidad, pero en líneas generales las naciones menos desarrolladas suelen presentar porcentajes de orgullo nacional sostenidos, si no crecientes y mayores que las desarrolladas. Entre estas últimas, donde predominan los llamados valores postmaterialistas, también existen países que presentan fuertes sentimientos de orgullo nacional (se sugiere que como reacción a la recepción de inmigrantes o a la integración en unidades supranacionales del tipo de la Unión Europea). En otros ha disminuido el sentimiento patriótico, lo cual no es signo de una mayor vinculación con una ciudadanía mundial. De hecho, en algunos países desarrollados donde ha disminuido el sentimiento patriótico, este se ha desplazado hacia unidades menores con mayor coherencia cultural (nacionalismos regionales). Encontramos, por tanto, un panorama complejo, pero la vinculación con el estado-nación sigue siendo importante (Inglehart, 2001, pp. 399-402). La llamada crisis de la identidad nacional, de la que hablamos antes, puede ser cierta en algunos países desarrollados, pero no supone una vinculación automática con una ciudadanía global y con entes políticos supranacionales. Más bien supone un recogerse en otras identidades comunitarias. $Y$, en algunos casos, la presencia de inmigrantes o la integración en entidades supranacionales puede incluso exacerbar el sentimiento patriótico nacional.

El caso de la Unión Europea es significativo para valorar el grado de identificación de los ciudadanos con su nación o con la propia Unión Europea, ya que es una de las entidades políticas supranacionales más exitosas y consolidadas. En el Eurobarómetro de mayo de 2015 se preguntó si en el futuro los europeos se veían como nacionales de su país, nacionales y europeos, europeos y nacionales, o solamente europeos. Los resultados variaban por países, pero para el conjunto de la Unión Europea un 38\% se veían solo como miembros de su nación, un 52\% como miembros de su nación y de la Unión Europea, un 6\% como miembros de la Unión Europea y de su país, y solamente un $2 \%$ como miembros de la Unión Europea ${ }^{4}$. El sentimiento de pertenencia al país en solitario o con más frecuencia de modo compartido con la Unión Europea era la opción mayoritaria.

A todo lo anterior podemos sumarle que la identidad cosmopolita como primera opción identitaria sigue teniendo unas dimensiones reducidas. Como informa Manuel Castells haciendo referencia al trabajo de Pipa Norris, que utilizaba la Encuesta Mundial de Valores: 


\begin{abstract}
"En cuanto al conjunto mundial, la proporción de los que se consideran primariamente ciudadanos del mundo, es decir, cosmopolitas, es del 13\%; la de los que se consideran primariamente de identidad nacional entendida como Estado-nación es del 38\%, y el resto (...) se considera como identidad local o regional prioritariamente" (Castells, 2010, p. 255).
\end{abstract}

Es decir, solamente un $13 \%$ de los habitantes del planeta se definen en primer lugar como ciudadanos del mundo. En una encuesta de 2016 encargada por el canal de televisión británico BBC a GlobalScan se preguntó en dieciocho países a los entrevistados si se veían más como ciudadanos globales que como ciudadanos de su país ${ }^{5}$. La suma de personas que afirmaban estar muy de acuerdo y parcialmente de acuerdo con esta afirmación era del $49 \%$ para el conjunto de países, siendo del $43 \%$ para la suma de parcialmente en desacuerdo y muy en desacuerdo. En algunos países el apoyo a la opción cosmopolita era sorprendentemente alto. En Nigeria el $73 \%$ y en España el 59\% estaban de acuerdo con la afirmación.

Ahora bien, cuando se les ofrecieron cinco opciones para definir su identidad principal los resultados fueron distintos. Para el conjunto de los países encuestados el $52 \%$ se definió como ciudadano de su nación, el $17 \%$ como ciudadano del mundo, el $11 \%$ como miembros de su comunidad local, el $9 \%$ se refirió a su tradición religiosa, y el $8 \%$ lo hizo respecto a su raza o cultura. En los casos señalados, en Nigeria el $68 \%$ se definió como ciudadano de su nación y solamente un $9 \%$ como ciudadano del mundo. En España el $28 \%$ como ciudadano de su nación y el $54 \%$ como ciudadano del mundo. Fue el único país en el que esta opción resultó mayoritaria. En líneas generales, la opción principal al definir la identidad primaria sigue siendo el estado-nación y, en algunos países, las comunidades locales, la tradición religiosa o la raza y la cultura. Solo el $17 \%$ se define en primer lugar como ciudadano del mundo.

Existe, por tanto, una cierta contradicción entre estas visiones. Los individuos de los países que pertenecen a la Organización para la Cooperación y el Desarrollo Económico (OCDE) se sienten menos ciudadanos globales que los de los países que no pertenecen a la misma. Sin embargo, los países en los cuales existe una mayor identificación primaria con la ciudadanía nacional suelen ser países que no pertenecen a la OCDE (por ejemplo, Rusia, Kenia, Nigeria o China). Es posible aventurar que las identidades tradicionales, entre ellas la ciudadanía nacional, siguen siendo las más importantes para los individuos, si bien la respuesta políticamente correcta sería la apuesta por una ciudadanía global. En los países menos desarrollados podría reflejar también un deseo de inclusión en la comunidad de países más desarrollados, lo cual no impediría la presencia de un fuerte sentimiento patriótico ${ }^{6}$.

Bronislaw Szerszynski y John Urry (2002) realizaron una investigación a través de focus groups en Inglaterra para indagar la extensión y la profundidad del cosmopolitismo. Encontraron que en ellos pocos se declaraban ciudadanos del mundo o desafiaban la identidad nacional tradicional. Sin embargo, hallaron lo que llamaron un cosmopolitismo banal impulsado sobre todo por los medios de comunicación transnacionales. Esto podría explicar, por un lado, la visión positiva del cosmopolitismo y la persistencia de las identidades nacionales y locales. De hecho, en un estudio hecho con padres se constató que estos veían más el cosmopolitismo como una forma de capital cultural con la que dotar a sus hijos en la era de la globalización que como un ideal ético (Weenink, 2008).

Un estudio posterior, basado en la citada Encuesta Mundial de Valores, trató de encontrar el perfil del cosmopolita, entendido como aquel individuo que expresaba mayor sentimiento de "pertenencia al mundo". Encontró que el cosmopolita suele ser una persona joven, ecologista, poco patriota, políticamente activa, con educación superior y con una actitud positiva hacia los inmigrantes en países donde hay mucha inmigración. Sin embargo, este perfil era distinto en algunos contextos. Por ejemplo, el conjunto de la población en los países de la antigua URSS era más cosmopolita que en otros lados, lo que interpretaron como falta de confianza en los estados surgidos tras su desintegración (Schueth y O'Loughlin, 2007).

Así pues, el estado-nación y, de un modo quizá no sorprendente, las comunidades locales y regionales siguen siendo la principal fuente de identidad. Además, tampoco existe un apoyo explícito hacia las instituciones propias del cosmopolitismo político real: "según los sondeos de opinión, es muy improbable que, en el futuro previsible, la mayoría de los ciudadanos de un país acepten la integración plena en un estado federal supranacional" (Castells, 2000, p. 297). La identificación con una ciudadanía mundial puede operar en la esfera identitaria junto al rechazo a un estado o a una federación de estados mundial. A veces se habla de patriotas cosmopolitas o cosmopolitas con raíces para referirse a esta situación. 


\section{DE MOCHILEROS Y EXPATRIADOS CORPORATIVOS}

Podría argumentarse, no obstante lo anterior, que en efecto la población en su conjunto es reacia a una ciudadanía global y que el sentimiento de identidad nacional sigue siendo fuerte y estando extendido, pero que ya existen colectivos globalizadores emergentes entre los cuales esta idea no es tan extraña. Si la globalización efectivamente supone una superación de las barreras nacionales y un debilitamiento de su soberanía y de la ciudadanía nacional, sería lógico suponer que la nueva ciudadanía global operará con más fuerza entre los colectivos ampliamente globalizados. Como mantienen Zlatko Skrbis y lan Woodward (2013), el cosmopolitismo puede verse como una práctica y ciertos colectivos como las elites corporativas internacionales pueden ser un buen ejemplo de estas prácticas.

A pesar de las dificultades que entraña la investigación con colectivos globalizados, existe cierto corpus empírico sobre algunos de ellos. Aquí nos centraremos en dos colectivos concretos: los mochileros (backpackers) y los expatriados corporativos. La elección no ha sido fruto del azar, sino de un interés intelectual. Llevamos tiempo investigando y escribiendo sobre los mismos. Además, el fenómeno del nomadismo global se acerca al cosmopolitismo, aunque no pueda establecerse una relación plena. Como afirma Norbert Bilbeny (2007, pp. 64-69), ser patriota o cosmopolita es sobre todo una manera de ser o de pensar. Por tanto, un viajero -lo haga por placer o por negocios- puede recorrer el mundo sin sentirse miembro del mundo ${ }^{7}$. En todo caso, en principio parece lógico pensar que entre los nómadas globales se produzcan actitudes cosmopolitas con más frecuencia que entre los patriotas. Es lo que pretendemos ver a continuación.

\subsection{Mochileros}

Los mochileros son un colectivo específico de turistas que suele emprender un viaje de larga duración por el extranjero en el que visitan destinos múltiples a los que viajan a través de un itinerario flexible que suelen autogestionar. Como mostró Anders Sørensen (2003), su origen es mayoritariamente occidental, acostumbran a ser jóvenes, con educación universitaria y viajan entre dos y dieciocho meses en momentos específicos de su vida (fin de estudios, divorcios o entre un trabajo y otro). En líneas generales, su perfil es el de ciudadanos de sociedades opulentas que toman un respiro de su vida cotidiana. Además, se ha planteado que los mochileros forman una subcultura específica (Martín-Cabello, 2014, pp. 172-176).
En principio, podría considerarse que una subcultura global de este tipo es un caldo de cultivo ideal para las actitudes cosmopolitas. Greg Richards y Julie Wilson (2004, p. 26) encontraron que entre las motivaciones expresadas por los mochileros para emprender su viaje se hallaba en primer lugar la de explorar otras culturas y en sexto lugar, de un total de diecinueve opciones, la de interactuar con personas de otros países. El viaje es visto por los mochileros como una experiencia ampliamente educativa (Martín-Cabello y García-Manso, 2015a). Por tanto, consideran el cosmopolitismo como una forma de capital cultural adquirible a través del viaje.

Sin embargo, la bibliografía sobre mochileros no ha explorado en profundidad las cuestiones de identidad nacional o cosmopolita. En líneas generales, la cuestión de la identidad se ha ceñido a la auto-percepción de los mochileros como "viajeros" o como "turistas". Una contraposición que es básica en esa subcultura, pero que nos aleja de la auto-percepción del mochilero más en general. Algunos estudios han tratado de mostrar que las Tecnologías de la Información y las Comunicaciones permiten la aparición de un sentimiento de comunidad con extraños (Adkins y Grant, 2007), que sería una forma de lo que más arriba se denominó cosmopolitismo banal. Aunque también es cierto que según algunos recuentos etnográficos la nacionalidad seguía siendo una de las formas de identificación básica entre mochileros, y que estos tendían a reunirse por motivos de nacionalidad y lengua compartida. Dicho de otro modo, los mochileros pueden sentirse miembros de una comunidad global de viajeros sin renunciar a su origen. Al fin y al cabo, tras su periplo debían regresar a su país a recuperar su vida corriente.

Asimismo, también se ha constatado que los mochileros en muchas ocasiones tienden a operar con grandes categorías geográficas que oscurecen las diferencias identitarias importantes para la población local. Era frecuente, por ejemplo, que los mochileros que viajaban por Latinoamérica consideraran al subcontinente como una gran unidad, minusvalorando las diferencias entre las diversas partes del mismo. Existen también criterios identitarios regionales entre los mochileros latinoamericanos, que se reconocían entre sí como miembros de una comunidad cultural diferenciada de la de los mochileros "gringos" (Martín-Cabello, 2014).

Respecto a las prácticas, se ha señalado que los mochileros tienden a relacionarse entre sí, habitualmente usando el inglés como lengua franca, y que sus 
contactos con la población local tienen a ser escasos y limitados a las relaciones comerciales. Además, acostumbran a seguir rutas prefijadas y a convivir en enclaves que reproducen el hogar fuera del hogar (hostales, refugios, cafeterías, etc.). Su modo de vestir, por otro lado, los unifica como colectivo y los diferencia de la población local de los países que visitan.

\subsection{Expatriados corporativos}

Los expatriados corporativos pueden definirse como trabajadores de empresas transnacionales o de burocracias internacionales que durante un tiempo prolongado y habitualmente de modo voluntario trabajan en el extranjero. Algunos estudios muestran que, en líneas generales, el grueso de los expatriados corporativos tiene una procedencia occidental (Expatriate Trends Study 2013: Understanding Their Perspective). En la bibliografía gerencial sobre la expatriación se ha prestado atención al hecho de que el cosmopolitismo tiene una correlación positiva con el deseo de expatriarse. Así, en encuestas elaboradas en Alemania y Corea del Sur, se encontró una fuerte correlación entre el cosmopolitismo y el deseo de trabajar en el extranjero (Froese, Jommersbach y Klautzsch, 2013). Antes mencionábamos el caso de los padres que consideraban que el cosmopolitismo era una forma de capital cultural que deseaban transmitir a sus hijos. Esto sin duda tiene su correlato en las empresas globales, que valoran positivamente el cosmopolitismo entre las características de sus empleados de "alto potencial". La expatriación es una característica que se exige a las elites directivas (Luci, 2014, p. 185).

Un asunto diferente es medir si los expatriados son realmente cosmopolitas, es decir, si se sienten ciudadanos del mundo y viven en prácticas cosmopolitas. La identidad cosmopolita de los expatriados no está clara, pues existen diversos rasgos a los cuales pueden adscribir su identidad. Por ejemplo, en algún estudio se ha encontrado que estos suelen sentirse miembros de una subcultura multinacional cuando están en contextos alejados de sus orígenes. Es el caso de los expatriados occidentales en Asia. Por el contrario, esos mismos expatriados occidentales pueden referirse a sus identidades nacionales cuando el entorno es occidental. Un australiano en Italia puede realzar sus rasgos nacionales en detrimentos de los cosmopolitas y, por el contrario, referirse a una cultura transnacional que lo une al italiano cuando se encuentra en Indonesia (Hipsher, 2008, p. 71).

En relación a las prácticas, algunos autores han señalado que los expatriados interactúan poco con los miembros de las comunidades locales en las que habitan (Fechter, 2007). De hecho, suelen hacerlo entre ellos y con los miembros de la cultura local más integrados en su mundo, sobre todo los compañeros de trabajo del país en el cual están expatriados (Beaverstock, 2002). También se ha descubierto que los expatriados más cosmopolitas suelen adaptar en mayor grado su conducta a los nuevos entornos que los menos cosmopolitas cuando su estancia es breve. Por el contrario, cuando es larga los no cosmopolitas se adaptan más y los más cosmopolitas se vuelven más hacia su cultura occidental (Grinstein y Wathieu, 2012). Diversos estudios etnográficos han subrayado que los expatriados tienden a generar enclaves a través de los cuales reproducen sus hogares en el extranjero (Lauring y Selmer, 2009; Porter, 2009; Sánchez, 2005).

Sin contar con estudios específicos de largo recorrido sobre el tema, es viable aventurar que los expatriados corporativos tienen una relación peculiar con el cosmopolitismo. Este es considerado como una forma de capital cultural y, sin duda, los rasgos propios del cosmopolitismo (apertura a otra cultura, valoración de lo foráneo, etc.) son reclamados como valiosos en el discurso explícito. Ahora bien, los recuentos etnográficos muestran una situación distinta en la esfera de las prácticas: creación de enclaves, valoración de lo propio frente a lo foráneo en estancias prolongadas, o relaciones con otros expatriados. Se puede encontrar, por tanto, la misma situación ambigua del cosmopolitismo dentro de este colectivo transnacional.

\section{CONCLUSIONES}

Los teóricos de la ciudadanía afirman que el concepto de ciudadanía nacional, es decir, aquella que liga la ciudadanía al estado-nación, está en crisis. Han argumentado sobre este punto en múltiples obras de carácter más o menos teorético. Como hemos tratado de mostrar, piensan que la consecuencia del debilitamiento de la ciudadanía nacional sería, por un lado, la emergencia de una ciudadanía flexible, a la carta, desagregada y jerarquizada; y, por otro lado, la aparición de una ciudadanía global, mundial o cosmopolita. Esta última, la ciudadanía cosmopolita, suele verse como una ciudadanía o bien superpuesta o bien enfrentada a la ciudadanía nacional. El proceso de globalización suele verse como el principal impulsor de esta transformación.

Tras la revisión de datos secundarios y de estudios que tratan de medir en el mundo el apoyo a los estados-nación (sentimiento patriótico) y a la ciudadanía mundial (sentimiento de pertenencia al mundo), he- 
mos comprobado que el entorno local, regional o nacional continúa siendo la principal fuente de identidad primaria para las personas. La identidad cosmopolita tiene unas dimensiones reducidas. No obstante, también es cierto que la opción me siento tan miembro de mi nación como del mundo o del mundo como de mi nación tiene un gran peso, aunque descompensado hacia la identidad nacional. Otro asunto es que, como plantean algunos estudios, se esté desarrollando un cosmopolitismo banal o de la vida cotidiana bajo el influjo de los medios de comunicación transnacionales.

De igual modo, nuestro trabajo ha explorado las evidencias disponibles sobre dos colectivos globalizados: los mochileros y los expatriados corporativos. La hipótesis de partida sostenía que estos colectivos podrían ser una avanzadilla en el apoyo a la ciudadanía global, ya que están más firmemente implicados en el proceso de globalización. La evidencia no deja de ser ambigua. Por esta razón, trataremos ambos colectivos de modo unificado en estas conclusiones, ya que existen continuidades notables entre la subcultura mochilera y la de los expatriados corporativos, como se ha tratado de mostrar en otro lugar (Martín-Cabello y García-Manso, 2015b), y porque su posicionamiento respecto al cosmopolitismo es similar. En ambos casos se suelen expresar ideales cosmopolitas: apertura al otro o valoración de las culturas foráneas, y se considera que el cosmopolitismo es una parte valiosa del capital cultural de las personas. Sin embargo, ambos colectivos suelen proceder de entornos occidentales $\mathrm{y}$, en cuanto a sus prácticas, existe cierta tendencia a crear enclaves y redes de mochileros y expatriados corporativos en el extranjero. Es decir, la retórica es claramente cosmopolita pero la práctica cotidiana no lo es tanto.

En definitiva, la ciudadanía global aparece como un recurso retórico importante entre las instituciones globales e incluso entre la ciudadanía, que compra la idea de ser un ciudadano del mundo. De hecho, se ha desarrollado un cosmopolitismo cotidiano fruto del influjo de las culturas globalizadas trasmitidas por la industria mediática. Sin embargo, la ciudadanía nacional no ha desaparecido. Al contrario, sigue siendo -junto a las identidades locales y regionales- la fuente de identidad primaria para la mayor parte de la población del planeta. Algunos colectivos globalizados muestran estas ambigüedades, al aunar una retórica cosmopolita con la defensa de la identidad ciudadana nacional o una vaga identidad transcultural (como mochilero o expatriado corporativo). En ese sentido es imprescindible seguir avanzando por estas líneas de investigación para validar si estos colectivos globales son una avanzadilla de una nueva identidad ciudadana global o, por el contrario, las identidades nacionales continúan siendo básicas incluso dentro de estos colectivos, como parecen apuntar los estudios previos.

\section{NOTAS}

1. Antes del siglo XVIII el concepto de ciudadanía estaba ligado a las ciudades-estado, mientras que a partir de ese momento comenzó a estarlo al estado-nación. Aquí nos referiremos a ciudanía como concepto surgido de la modernidad. Sobre la ciudadanía en el mundo antiguo véase el trabajo de Ellen Meiksins Wood (2011). En esta obra se describe un lento declinar del concepto de ciudadanía desde la Antigüedad hasta la Edad Media. "Lo que resulta más ambiguo y paradójico en la tradición occidental de la teoría política, que nació en la comunidad cívica de la antigua Grecia, es que sus ideales fundacionales de ciudadanía e igualdad fueron, casi desde el principio, adaptados para que sirvieran a la causa de la desigualdad y la dominación" (Wood, 2011, p. 300).

2. Se habla, por ejemplo, de un nacionalismo cívico frente a un nacionalismo étnico, estando el primero basado en una asociación racional de ciudadanos y el segundo en la sangre y la cultura común compartida (Smith, 2004, pp. 57-60). Algunos autores, sin embargo, abogan por no considerar nacionalismo (étnico) y ciudadanía como realidades excluyentes. Para ello hablan de una ciudadanía diferenciada que integre las demandas de los grupos étnicos en su seno (Gómez Rodríguez, 2004; Kymlicka, 1996)

3. Una buena comparación sobre las tradiciones de ciudadanía y acerca del tratamiento que se da a los grupos étnicos en Europa y Estados Unidos se encuentra en Kroes (2002).

4. https://goo.gl/78tBvs

5. http://www.globescan.com/ news-and-analysis/press-releases/ press-releases-2016/383-global-citizenship-a-growing-sentiment-amongcitizens-of-emerging-economies-global-poll.html
6. El caso de España requeriría una explicación diferente que sobrepasa los límites de esta contribución. Pero resultan significativos los porcentajes de respuesta en torno a las opciones identitarias primarias ofrecidas: ciudadano español (28\%), ciudadano del mundo (54\%), la comunidad o área local menor que el país (5\%), la tradición religiosa (5\%) y la raza o la cultura (5\%). Hicimos una consulta a la persona encargada de la encuesta en España, que realizó la empresa Sigma Dos Int., para aclarar cómo se formuló la pregunta, sin recibir contestación por su parte. En todo caso, los datos de la Encuesta Mundial de Valores muestran que la proporción de los que contestan sentirse identificados en primer lugar con su localidad, con la nación o con la región es mucho mayor que la que arroja este estudio (consultada a través del Banco de datos ASEP-JDS).

7. Es lo que el escritor Rafael Argullol (2016, 2 de enero) llamó el provinciano global. 


\section{BIBLIOGRAFÍA}

Adkins, B. y Grant, E. (2007). Backpackers as a community of strangers: The interaction order of an online backpacker notice board. Qualitative Sociology Review, III (2), pp. 188-201.

Aguilera Portales, R. (2011). La ciudadanía ante la globalización: nuevos modelos de ciudadanía postnacional y transcultural. Revista de Derecho UNED, 8, pp. 13-48.

Anchustegui Igartua, E. (2012). Estado de bienestar, ciudadanía y globalización: el debate sobre los derechos sociales. Daímon. Revista Internacional de Filosofía 56, pp. 37-51.

Anderson, J. (1995). The exaggerated death of the nation-state. En Anderson, J., Brock, C. y Cochrane, A. (eds.) A Global World? Re-Ordering Political Space. Oxford: The Open University Press-Oxford University Press, pp. 65-112.

Argullol, R. (2016, 2 de enero). Provincianos y cosmopolitas. El País. [En línea] Disponible en: http://elpais.com/elpais/2015/12/18/ opinion/1450431738_159745.htm

Bauman, Z. (2010). La globalización. Consecuencias humanas. México: Fondo de Cultura Económica.

Beaverstock, J. V. (2002). Transnational elites in global cities: British expatriates in Singapore's financial district. Geoforum, 33 (4), pp. 525-538. http://dx.doi. org/10.1016/S0016-7185(02)00036-2

Beck, U. (2008). ¿Qué es la globalización? Falacias del globalismo, respuestas a la globalización. Barcelona: Paidós.

Beck, U. y Beck-Gernsheim, E. (2003). La individualización. El individualismo institucionalizado y sus consecuencias políticas y sociales. Barcelona: Paidós.

Bendix, R. (1974). Estado nacional y ciudadanía. Buenos Aires: Amorrortu.

Benhabib, S. (2006). Las reivindicaciones de la cultura. Igualdad y diversidad en la era global. Madrid: Katz.

Berger, P. L. y Huntington, S. P. (comps.) (2002). Globalizaciones múltiples. La diversidad cultural en el mundo contemporáneo. Barcelona: Paidós.

Bilbeny, N. (2007). La identidad cosmopolita. Los límites del patriotismo en la era global. Barcelona: Kairós.

Bokser, J. (2006). Ciudadanía, procesos de globalización y democracia. Revista En- foques. Ciencia Política y Administración Pública, 5, pp. 163-189.

Bokser, J. y Salas-Porras Soulé, A. (1999). Globalización, identidades colectivas y ciudadanía. Política y cultura, 12, pp. 25-52

Borja, J. (2002). Ciudadanía y globalización. Revista del CLAD Reforma y Democracia, 22, pp. 1-11.

Castells, M. (2000). La era de la información. Economía, sociedad y cultura (Vol. 2. El poder de la identidad). Madrid: Alianza.

Castells, M. (2010). Globalización e identidad. Quaderns de la Mediterrània, 14, pp. 254-262.

Castles, S. (2003). Jerarquías de ciudadanía en el nuevo orden global. Anales de la Cátedra Francisco Suárez, 37, pp. 9-33.

Castles, S. y Davidson, A. (2000). Citizenship and Migration: Globalization and the Politics of Belonging. Basingstoke: Palgrave.

Colomer, J. M. (2015). El gobierno mundial de los expertos. Barcelona: Anagrama.

Cortina, A. (1997). Ciudadanos del mundo. Hacia una teoría de la ciudadanía. Madrid: Alianza.

Dahl, R. A. (2014). La democracia. Barcelona: Ariel.

Delanty, G. (2000). Citizenship in a Global Age: Society, Culture, Politics. Buckingham: Open University Press.

Díaz Velázquez, E. (2009). El estudio sociopolítico de la ciudadanía: fundamentos teóricos. Intersticios. Revista sociológica de pensamiento crítico, 3 (1), pp. 33-46.

Eagleton, T. (2001). La idea de cultura. Una mirada política sobre los conflictos culturales. Barcelona: Paidós.

Fechter, A. M. (2007). Transnational Lives: Expatriates in Indonesia. Aldershot, UK: Ashgate.

Froese, F. J., Jommersbach, S. y Klautzsch, E. (2013). Cosmopolitan career choices: a cross-cultural study of job candidates' expatriation willingness. The International Journal of Human Resource Management, 24 (17), pp. 3247-3261. http://dx.doi.org/1 $0.1080 / 09585192.2013 .770782$

Giddens, A. (1999). Consecuencias de la modernidad. Madrid: Alianza.

Giddens, A. (2002). Un mundo desbocado Los efectos de la globalización en nuestras vidas. Madrid: Taurus.
Giraldo Jiménez, F. H. (2000). Ciudadanía y globalización. Estudios Políticos, 16, pp. 141-150.

Gómez Rodríguez, S. (2004). Nacionalismo y ciudadanía en la era de la globalización. Aposta. Revista de Ciencias Sociales, 5, pp. 1-28.

González García, E. y Chacón-López, H. (2014). Sobre el concepto y modelos de ciudadanía.Etic@net. Revista científica electrónica de Educación y Comunicación en la Sociedad del Conocimiento, 14 (2), pp. 288-311.

Grinstein, A. y Wathieu, L. (2012). Happily (mal)adjusted: Cosmopolitan identity and expatriate adjustment. International Journal of Research in Marketing, 29 (4), pp. 337-345. http://dx.doi. org/10.1016/j.ijresmar.2012.03.003

Heater, D. (2007). Ciudadanía. Una breve historia. Madrid: Alianza.

Held, D. (2012). Cosmopolitismo. Ideales y realidades. Madrid: Alianza.

Hipsher, S. A. (2008). Expatriates in Asia: Breaking Free from the Colonial Paradigm. Oxford: Chandos. https://doi. org/10.1533/9781780632469

Hormigos Ruiz, J. y Oda Ángel, F. (2014). Identidades culturales en un mundo en movimiento. Reflexiones desde la sociología. methaodos. revista de ciencias sociales, 2 (2), pp. 244-255. http://dx.doi. org/10.17502/m.rcs.v2i2.55

Houellebecq, M. (2015). Sumisión. Barcelona: Anagrama.

Huntington, S. P. (2004). ¿Quiénes somos? Desafíos de la identidad nacional estadounidense. Barcelona: Paidós.

Inglehart, R. (2001). Modernización y posmodernización. El cambio cultural, económico y político en 43 sociedades. Madrid: CIS.

Kroes, R. (2002). Ciudadanía y globalización. Europa frente a Norteamérica. València: Universitat de València.

Kymlicka, W. (1996). Ciudadanía multicultural. Barcelona: Paidós.

Lamo de Espinosa, E. (1996). Fronteras culturales. En Lamo de Espinosa, E. (ed.). Culturas, estados y ciudadanos. Una aproximación al multiculturalismo en Europa. Madrid: Alianza, pp. 18-30.

Lauring, J. y Selmer, J. (2009). Expatriate compound living: An ethnographic 
field study. International Journal of Human Resource Management, 20 (7), pp. 1451-1667. http://dx.doi. org/10.1080/09585190902983215

Levín, S. (2004). Los desafíos de la ciudadanía en las sociedades contemporáneas. Revista SAAP, 2 (1), pp. 35-68.

Lipovertsky, G. (2004). La era del vacío. Ensayos sobre el individualismo contemporáneo. Barcelona: Anagrama.

Luci, F. (2014). La "internacional de los managers": cultura cosmopolita, movilidad internacional y éxito corporativo en las grandes empresas globales. A Contracorriente. Una revista de historia social y literatura de América Latina, 11 (2), pp. 166-194.

Maalouf, A. (2010). Identidades asesinas. Madrid: Alianza.

Mandujano, M. (2009). Ciudadanía y globalización. Notas fundamentales desde el cosmopolitismo subalterno. Astrolabio. Revista internacional de filosofía, 9, pp. 96-105.

Marshall, T. H. y Bottomore, T. (1998). Ciudadanía y clase social. Madrid: Alianza.

Martín-Cabello, A. (2013). Sobre los orígenes del proceso de globalización. methaodos. revista de ciencias sociales, 1 (1), pp. 7-20. http://dx.doi. org/10.17502/m.rcs.v1i1.22

Martín-Cabello, A. (2014). El turismo "backpacker" en Chile como expresión de una subcultura juvenil global. Cuadernos de Turismo, 34, pp.165-188.

Martín-Cabello, A. (2015). La desconfianza en las instituciones como expresión del cambio político y cultural. Aposta. Revista de Ciencias Sociales, 67, pp. 33-70.

Martín-Cabello, A. y García-Manso, A. (2015a). Aprender a través del viaje: el turismo mochilero como experiencia educativa. Opción, 31 (1), pp. 430-448.

Martín-Cabello, A. y García-Manso, A. (2015b). Una aproximación a las relaciones entre el turismo mochilero y la cultura corporativa global. Revista de Antropología Experimental, 15, pp. 55-72. http:// dx.doi.org/10.17561/rae.v0i15.2365

Münch, R. (2001). Nation and Citizenship in the Global Age. Basingstoke: Palgrave. https://doi.org/10.1057/9780230512245

Niederberger, A. (2012). Reinventar la ciudadanía. Acerca de la conexión entre democracia, derechos y legitimidad en el orden político global. Eidos, 17, pp. 134-167.
Ong, A. (1999). Flexible Citizenship. The Cultural Logics of Transnationality. Durham: Durham University Press.

Ortiz, R. (1998). Los artífices de una cultura mundializada. Santa Fe de Bogotá: Siglo del Hombre-Fundación Social.

Parada Barrera, C. S. (2009). Hacia un nuevo concepto de ciudadanía mundial. Via Iuris, 7, pp. 98-111.

Porter, L. (2009). Transnational spaces: U.S. expatriates recreating home in Costa Rica. International Journal of Interdisciplinary Social Sciences, 3 (10), pp. 217223. https://doi.org/10.18848/18331882/CGP/v03i10/52731

Richards, G. y Wilson, J. (2004). The global nomad: motivations and behavior of independent travelers worldwide. En Richards, G. y Wilson, J. (eds.). The Global Nomad. Backpacker Travel in Theory and Practice. Clevedon, UK: Channel View Publications, pp. 14-39.

Sánchez, S. (2005). Las familias de expatriados brasileños en México. En Pérez Lizaur, M. (coord.). Ejecutivos de alto nivel: ¿una elite global? México: Universidad Iberoamericana, pp. 163-197.

Sánchez-Cuenca, I. (2010). Más democracia, menos liberalismo. Madrid: Katz.

Sánchez-Cuenca, I. (2016). La desfachatez intelectual. Escritores e intelectuales ante la política. Madrid: Los Libros de la Catarata.

Santiago Juárez, R. (2009). Ciudadanía cosmopolita y globalización. Una revisión del pensamiento kantiano. Universitas. Revista de Filosofía, Derecho y Política, 9, pp. 5-20.

Santiago Juárez, R. (2015). La ciudadanía en el escenario de la globalización. Revista Chilena de Derecho y Ciencia Política, 6 (1), pp. 13-34.

Schueth, S. y O’Loughlin, J. (2007). Belonging the world: Cosmopolitanism in geographic context. Geoforum, 39 (2), pp. 926-941. http://dx.doi.org/10.1016/j. geoforum.2007.10.002

Sen, A. (2007). Identidad y violencia. Madrid: Katz.

Seoane Pinilla, J. (2009). Globalización vs. Ciudadanía (cosmopolita). Astrolabio. Revista internacional de filosofía, 9, pp. 195-203.
Skrbis, Z. y Woodward, I. (2013). Cosmopolitanism. Uses of the Idea. London: Sage. https://doi.org/10.4135/9781446288986

Skrbis, Z., Kendall, G. y Woodward, I. (2004). Locating cosmopolitanism. Between humanist ideal and grounded social category. Theory, Culture and Society, 21 (6), pp. 115-136. http://dx.doi. org/10.1177/0263276404047418

Smith, A. D. (2004). Nacionalismo. Teoría, ideología e historia. Madrid: Alianza.

Sørensen, A. (2003). Backpacker Ethnography. Annals of Tourism Research, 30 (4), pp. 847-867. http://dx.doi.org/10.1016/ S0160-7383(03)00063-X

Swedberg, R. (2016): El arte de la teoría social. Madrid: CIS.

Szerszynski, B. y Urry, J. (2002). Cultures of cosmopolitanism. The Sociological Review, 50 (4), pp. 461-481. http://dx.doi. org/10.1111/1457-954X.00394

Sztompka, P. (2008). Sociología del cambio social. Madrid: Alianza.

Todorov, T. (2010). Nosotros y los otros. Reflexiones sobre la diversidad humana. Madrid: Siglo XXI.

Velasco, J. C. (2003). Para leer a Habermas. Madrid: Alianza.

Vior, E. J. (2011). El afianzamiento de la idea de nación en la Revolución Francesa y sus consecuencias para la modernidad. Passagens. Revista Internacional de História Política e Cultura Jurídica, 3 (2), pp. 239-263. http://dx.doi. org/10.5533/1984-2503-20113205

Wallerstein, I. (2007). Universalismo europeo. El discurso del poder. Madrid: Siglo XXI.

Weenink, D. (2008). Cosmopolitanism as a form of capital. Parents preparing their children for a globalizing world. Sociology, 42 (6), pp. 1089-1106. http://dx.doi. org/10.1177/0038038508096935

Wood, E. M. (2011). De ciudadanos a señores feudales. Historia social del pensamiento político desde la Antigüedad hasta la Edad Media. Barcelona: Paidós.

\section{Otros recursos}

Expatriate Trends Study 2013: Understanding Their Perspective. Executive Summary. [En línea]. Disponible en https:// www.cignaglobalhealth.com/assets/ docs/we-know-expats/2013-global-mobility-exec-summary.pdf 